\title{
Estimating The Impact of Vice-Presidential Candidates on the 2020 General Election
}

\author{
Akhil Rajan*
}

July 28,2020

\begin{abstract}
We conducted a survey experiment to estimate how potential Democratic nominees for Vice President (Elizabeth Warren, Kamala Harris, Stacey Abrams, Susan Rice, Tammy Duckworth, Keisha Lance Bottoms, Tammy Baldwin, and Val Demings) can be expected to be evaluated in the context of the 2020 general election. To do so, we randomly assigned survey respondents information about the candidates using vignettes that distill the dominant narratives (both pro- and con-) surrounding the candidate. We show that the vignettes tend to equalize favorability ratings across candidates, though in general the lesser-known candidates do not fully catch up to the more well-known candidates. In the control condition emulating standard polling methodologies, the candidates viewed most favorably are Warren and Harris, with 46/100 average favorability, followed by Abrams at 43, and the remainder at 42 or below. In the treatment condition where respondents have been exposed to information, the candidates viewed most favorably are Harris (46), Warren (45), and Bottoms (45), followed by Duckworth, Rice, and Abrams, all at 44 . While we fail to find statistically significant effects of the vignettes on reported vote intention, the results for vote intention substantively agree with those for favorability.
\end{abstract}

\section{Introduction}

It is widely understood among both practitioners and political scientists that early elections polls have little predictive power toward the end result. Pollsters often add the caveat that their work represents a snapshot of

\footnotetext{
${ }^{*}$ Department of Political Science, Yale University. This study was preregistered with OSF, including a preanalysis plan at https://osf.io/3zx6p/. The research was deemed exempt by the Yale University IRB (HSC \#2000028533). We thank Peter Aronow for extensive guidance with this project, including collaboration on the pre-analysis plan. We also thank Grace Kang and John Ternovski for research assistance and helpful comments; Chris Schuck for copyediting support; and Josh Kalla and Alex Coppock for helpful comments. The author discloses a \$1 donation to Kamala Harris in October 2018.
} 
the electorate at a particular time: natural voter movement and shock events can easily upend the results of an early poll in the intervening months leading up to an election.

Before campaigns make their competing cases to the public, voters often begin an election cycle with little information about the candidates. Since voters are believed to value substantive representation over descriptive characteristics, the few baseline cues they receive about a candidate at the outset (e.g. from their name, associations, or limited press coverage) have little relevance to their eventual decision-making (Arnesen et al. 2019). Thus, as voters garner more information over the course of the campaign, their appraisals of the candidates change and conform toward the eventual result of the election (Gelman and King 1993). Name recognition alone may affect respondents' support for a candidate, and so the biases of early polls cannot be assumed to be symmetric across candidates (Panagopoulos and Green 2008; Kam and Zechmeister 2013). An inability to capture the evolution in voters' information sets, typically driven by campaigns, has long been seen as an inherent defect in the use of polls to predict outcomes.

A common version of this problem of polling candidates with temporarily low name recognition arises in the selection of vice presidential nominees. Though the Vice President is arguably the second most visible political figure in the country, the candidates for the position are often unknown to most Americans before selection. This factor makes picking a running mate—one of the most important decisions of any presidential candidate's campaign—nearly impossible to poll through traditional means.

We consider a simple approach for estimating how the candidate might be evaluated in the general election: informing survey respondents about the candidates before polling them. This is accomplished by distilling positive and negative messaging about the candidates used in prior political campaigns into vignettes. Respondents read about a candidate's background, accomplishments, and associated scandals or controversies—much as they would over the course of the political campaign—before offering an evaluation. The idea of informing survey respondents is not new in the social sciences. Previous work has shown that vignette experiments echo behavioral outcomes "remarkably well" (Hainmueller et al. 2018). Information-based manipulations have been widely used to study the electoral impacts of political scandals among hypothetical candidates (e.g., Eggers, Vivyan, and Wagner 2018; Barnes et al. 2018; Gaskins et al. 2018; Doherty et al. 2011; Doherty et al. 2014; Funk 1996). A few scholars have extended this work to real-world candidates (Green et al. 2018; Berinsky et al. 2010), but generally this work has been limited to publicizing scandals among already-known candidates (for a review, see Incerti 2020), rather than exposing voters to holistic portrayals of unknown candidates. Most recently, in the context of the 2020 presidential election, Broockman and Kalla (2020) utilize vignettes to understand how primary candidates' support would fare in the face of attacks. Similarly, while some campaigns 
test the efficacy of individual messages on vote choice, candidate vignettes do not appear to be widely deployed in political polling.

We evaluate this approach using a randomized survey experiment on public opinion about eight potential Democratic candidates in the 2020 vice presidential selection process conducted during the week of July 13 , 2020. These candidates are:

- Elizabeth Warren, Senator from Massachusetts

- Kamala Harris, Senator from California

- Stacey Abrams, Former Minority Leader of the Georgia House of Representatives

- Susan Rice, Former National Security Advisor

- Tammy Duckworth, Senator from Illinois

- Keisha Lance Bottoms, Mayor of Atlanta

- Tammy Baldwin, Senator from Wisconsin

- Val Demings, US Representative from Florida

The candidates naturally provide a great deal of variation in visibility. Although Warren and Harris are known to most Americans, candidates like Bottoms, Baldwin and Demings are relatively unknown.

Our results demonstrate that informing voters makes a difference. Our primary hypothesis- that the vignettes would affect favorability — was borne out. The effects were primarily evident for candidates with low name recognition-Duckworth, Bottoms, Baldwin, and Demings—-suggesting that standard polling tends to penalize candidates with low name recognition. Effects on stated vote intentions were smaller, and did not reach the threshold of statistical significance. These findings are shown to largely replicate-with some loss of precision-in the subsamples of battleground states, registered voters, and Democrats. The findings do not replicate among the subsample of Republicans. We also demonstrate the perils of discarding respondents who do not recognize the name of a candidate, and show that this practice has the potential to gravely bias estimates.

\section{Survey Design}

Our survey experiment was conducted entirely online using a nationally representative sample $(N=2,863)$ supplied by Lucid Theorem between July 14th and 17th, 2020, roughly two weeks before Vice President Biden's 
scheduled announcement of his running mate. Previous studies have shown that Lucid tracks well with national benchmarks in the context of past political science experiments (Coppock and McClellan 2019). After screening subjects based on an initial consent form and attention check, we began by collecting demographic information about our respondents. In addition to the pre-supplied demographic information from Lucid (gender, household income, age, education, and party ID) we also captured information about state of residence, ideology, and registered voter status of respondents. We then measured baseline name recognition for all candidates. Appendix A presents summary statistics for the sample at hand, which demonstrate that the sample broadly represents national demographics.

Our survey instrument randomly assigned respondents to either read vignettes about three randomly selected candidates $(75 \%)$ or receive three placebo vignettes (control, $25 \%$ ). The vignettes for candidates were standardized and followed the same formatting, always containing one positive paragraph and one negative paragraph. The positive paragraphs were designed to be as close as possible to previous biographies promoted by candidates (either on campaign or personal websites), while ensuring uniformity. The first few sentences of each positive paragraph detailed the same general biographical information for all candidates, including family and educational background. The next few sentences detailed the candidate's professional background before they entered their latest governing position. The positive paragraph ended with a summary of the candidate's achievements in the last governing position they held. The negative paragraph summarized the three main criticisms leveled against the candidates by Republican opponents in the past. These arguments hued as close as possible to the attack ads and press releases by opponents, the RNC or major media investigations. The three placebo vignettes were descriptions of three of the four highest-grossing movies of 2010, which followed a similar length and character count as the candidate vignettes, without priming a political response. ${ }^{1}$ These vignettes are included in Appendix B.

After exposing respondents to these vignettes (either treatment or placebo), we asked voters to evaluate all potential vice presidential candidates. We measured:

1. Vote intention: "If the race for the White House were held today, and the Republican ticket was Donald Trump (President) and Mike Pence (Vice President), who would you vote for if the Democratic ticket was Joe Biden (President) and ...:

\section{Choices for each candidate: [The Republican Ticket] [The Democratic Ticket] [Third Party] [Would not vote]}

\footnotetext{
${ }^{1}$ We chose to exclude the number 3 highest grossing movie, Harry Potter and the Deathly Hallows - Part 1, because author JK Rowling was embroiled in controversy at the time of this survey.
} 
This was operationalized as whether respondents would vote for the Democratic ticket [coded as 1], the Republican ticket [coded as -1], a third party [coded as 0], or would not vote / no answer [coded as 0] if this person were chosen as the Democratic VP nominee.

2. Favorability: "On a scale of 0 (extremely unfavorable) to 100 (extremely favorable), how favorably do you view the following candidates?"

(Answers recorded on sliders)

3. Manipulation check (candidate knowledge): "Which positions have the following candidates held? Check all that apply. If none apply, please leave the boxes blank."

Choices for each candidate: [Member of the US Senate] [Member of the US House of Representatives] [Governor] [Member of a State House of Representatives] [Mayor] [US National Security Advisor] [ [Don't know/Not sure]

\section{Model and Estimation}

Consider the regression model

$$
Y_{h c i}=a_{h c}+b_{h c 1} D_{1 i}+\ldots+b_{h c 8} D_{8 i}+X_{i} B_{h c}+\varepsilon_{i}
$$

where $E\left[\varepsilon_{i} \mid D_{i 1}, \ldots, D_{i 8}, X_{i}\right]=0$. This model is motivated by (i) randomization and (ii) the assumption of a linear conditional expectation function.

$Y_{h c i}$ refers to the given outcome (vote intention $[\mathrm{h}=1]$, favorability $[\mathrm{h}=2]$ ) reported by respondent $i$ for a particular candidate $c$ (Warren, Harris, Abrams, Rice, Duckworth, Bottoms, Baldwin, Demings). In favorability regressions, observations with missing $Y_{2 c i}$ were dropped. ${ }^{3}$ Each $D_{k i}$ is an indicator variable for whether

\footnotetext{
${ }^{2}$ The preanalysis plan incorrectly omitted the category of US National Security Advisor, although this category was correctly included in the survey.

${ }^{3}$ In this data, missingness was under $2 \%$, implying the that the worst-case bias for both control and vignette means is under 2 points. Missingness was also highly correlated across candidates, with the lowest estimated pairwise correlation at 0.74 . In a non-preregistered analysis using missingness as an outcome, however, we reject the global null that the vignettes have an effect on missingness with $p=0.02$.
} 
respondent $i$ received a vignette about candidate $k . X_{i}$ is a vector of covariates for respondent $i$ : gender, age, education, indicators for US census region, income, PID, ideology, name recognition for all 8 candidates. Age, education, income, PID and ideology were treated as continuous. The income variable was formed by taking the midpoint of the ranges reported by Lucid. Covariates with missing data were mean-imputed. All 16 models (for each $h \in\{1,2\}, c \in\{1, \ldots, 8\}$ ) were fit jointly using seemingly unrelated regression (suest in Stata) with heteroskedasticity-robust variance-covariance matrix for inference.

Our inferential targets can be concisely described under our assumption of linearity. First, we are interested in control means:

$$
E\left[Y_{h c i} \mid D_{1 i}=\ldots=D_{8 i}=0, X_{i}\right]=a_{h c}+E\left[X_{i}\right] B_{h c i}
$$

Next, we are interested in the treatment means:

$$
E\left[Y_{h c i} \mid D_{c i}=1, D_{-c i}=0, X_{i}\right]=a_{h c}+b_{h c c}+E\left[X_{i}\right] B_{h c i},
$$

where $D_{-c i}$ denotes the treatment vector of all candidates other than c.

Finally, we are interested in our main effect estimates. The main effects correspond to the effect when only one candidate is treated, or the difference between the two above quantities. This is equal to $b_{h c c}$. Control/treatment means and standard errors will be computed using the margins command in Stata.

\section{Results}

\subsection{Candidate Knowledge}

As expected, respondents registered low levels of familiarity with many of the potential 2020 Democratic vice presidential aspirants. For example, only around one in four voters reported recognizing the names of Wisconsin Senator Tammy Baldwin or US Representative Val Demings.

Accordingly, we also conducted an non-preregistered analyses substituting missing outcomes with a score of 50 . We find that the results do not substantively change when handling missing data in this matter, with the largest difference in an estimated quantity for the full sample being 0.3. The full sample estimates using this imputation procedure are reported in Appendix C. 
Table 1: Name Recognition

$\begin{array}{lr}\text { \% Recognizing Candidate } \\ \text { Candidate } & \text { Estimate } \\ \text { Warren } & \mathbf{8 5 . 6} \pm 1.3 \\ \text { Harris } & \mathbf{7 2 . 4} \pm 1.6 \\ \text { Abrams } & \mathbf{5 5 . 6} \pm 1.8 \\ \text { Rice } & \mathbf{5 0 . 4} \pm 1.8 \\ \text { Duckworth } & \mathbf{3 7 . 6} \pm 1.8 \\ \text { Bottoms } & \mathbf{2 9 . 5} \pm 1.7 \\ \text { Baldwin } & \mathbf{2 5 . 6} \pm 1.6 \\ \text { Demings } & \mathbf{2 4 . 6} \pm 1.6\end{array}$

NOTE: Point estimates represent pre-treatment estimates of name recognition as described above. Uncertainty represents $95 \%$ confidence intervals. $N=2,863$

We hypothesized that equipping voters with information would increase knowledge of the individual candidates. To test this hypothesis, we examined our manipulation check to ascertain whether our treatments heightened the proportion of respondents who could correctly identify the political offices that a candidate had held.

For this manipulation check, we modified our model (Equation 1) to have the outcome variable $Y_{3 c i}$, which is a binary variable indicating if respondent $i$ correctly identified the highest elected office held by the potential candidate $c$. The following Table 2 outlines both point estimates for candidate knowledge in treatment and control, as well as the effect size of the difference.

Table 2: Effect of Information on Candidate Knowledge

\begin{tabular}{lrrr}
\multicolumn{3}{c}{ \% Correctly Identifying Highest Office Held } \\
Candidate & Control & Vignette & Effect \\
Warren & $\mathbf{4 5 . 1} \pm 3.1$ & $\mathbf{4 9 . 6} \pm 4.0$ & $\mathbf{4 . 6} \pm 3.6$ \\
Harris & $\mathbf{3 6 . 6} \pm 3.0$ & $\mathbf{4 8 . 1} \pm 4.1$ & $\mathbf{1 1 . 5} \pm 3.7$ \\
Abrams & $\mathbf{1 4 . 1} \pm 2.3$ & $\mathbf{2 4 . 1} \pm 3.4$ & $\mathbf{1 0 . 0} \pm 3.1$ \\
Rice & $\mathbf{2 3 . 2} \pm 2.6$ & $\mathbf{4 1 . 3} \pm 3.7$ & $\mathbf{1 8 . 1} \pm 3.4$ \\
Duckworth & $\mathbf{1 5 . 5} \pm 2.3$ & $\mathbf{2 4 . 1} \pm 3.6$ & $\mathbf{8 . 6} \pm 3.3$ \\
Bottoms & $\mathbf{2 0 . 1} \pm 2.4$ & $\mathbf{3 9 . 9} \pm 3.7$ & $\mathbf{1 9 . 8} \pm 3.5$ \\
Baldwin & $\mathbf{1 0 . 9} \pm 2.1$ & $\mathbf{1 9 . 7} \pm 3.3$ & $\mathbf{8 . 8} \pm 3.1$ \\
Demings & $\mathbf{1 2 . 1} \pm 2.1$ & $\mathbf{2 1 . 1} \pm 3.3$ & $\mathbf{9 . 0} \pm 3.0$
\end{tabular}

NOTE: Point estimates represent control, treatment, and effect estimates as described above. Uncertainty 
represents $95 \%$ confidence intervals. $N=2,863$

Every candidate vignette resulted in a statistically significant increase in the percentage of respondents that could correctly identify the highest office held by the candidate. We also performed a global Wald test against the null hypothesis $b_{311}=b_{322}=\ldots=b_{388}=0$, which returned $p<0.0001$. This finding suggests that our manipulation was successful in increasing knowledge of the candidates. Furthermore, both treatment and control outcomes largely follow the pattern of name recognition, suggesting that self-reports of name recognition can be seen to proxy for actual knowledge of the candidate.

\subsection{Favorability}

Our main quantity of interest was candidate favorability. Our primary hypothesis was that exposure to our vignettes would move attitudes about favorability. The left panel of Table 3 displays our results.

Table 3: Effect of Information on Favorability and Vote Intention

\begin{tabular}{|c|c|c|c|c|c|c|c|}
\hline \multicolumn{4}{|c|}{ Favorability (0-100) } & \multicolumn{4}{|c|}{ Vote Intention (R: -1, D: 1, NV/DK: 0) } \\
\hline Candidate & Control & Vignette & Effect & Candidate & Control & Vignette & Effect \\
\hline Warren & $\mathbf{4 6 . 3} \pm 2.0$ & $\mathbf{4 5 . 1} \pm 2.6$ & $-\mathbf{1 . 2} \pm 2.3$ & Warren & $.13 \pm .05$ & $. \mathbf{1 2} \pm .06$ & $-.01 \pm .05$ \\
\hline Harris & $\mathbf{4 6 . 3} \pm 2.0$ & $\mathbf{4 6 . 2} \pm 2.6$ & $-\mathbf{0 . 1} \pm 2.3$ & Harris & $.12 \pm .05$ & $. \mathbf{1 5} \pm .06$ & $.04 \pm .05$ \\
\hline Abran & $\mathbf{4 3 . 2} \pm 1.8$ & $\mathbf{4 3 . 6} \pm 2.4$ & $\mathbf{0 . 4} \pm 2.1$ & Abrams & $.07 \pm .04$ & $. \mathbf{1 0} \pm .06$ & $.03 \pm .05$ \\
\hline Rice & $\mathbf{4 2 . 2} \pm 1.8$ & $\mathbf{4 4 . 3} \pm 2.4$ & $\mathbf{2 . 1} \pm 2.2$ & Rice & $.07 \pm .04$ & $. \mathbf{1 0} \pm .06$ & $.03 \pm .05$ \\
\hline Duckwo & $\mathbf{4 1 . 1} \pm 1.8$ & $\mathbf{4 4 . 4} \pm 2.4$ & $\mathbf{3 . 3} \pm 2.2$ & Duckworth & $.06 \pm .04$ & $.06 \pm .06$ & $.00 \pm .05$ \\
\hline Bottoms & $\mathbf{4 1 . 6} \pm 1.8$ & $\mathbf{4 4 . 7} \pm 2.4$ & $\mathbf{3 . 0} \pm 2.1$ & Bottoms & $.09 \pm .05$ & $.13 \pm .06$ & $.05 \pm .05$ \\
\hline Baldwin & $\mathbf{3 7 . 5} \pm 1.7$ & $\mathbf{4 1 . 1} \pm 2.2$ & $3.6 \pm 2.0$ & Baldwin & $.04 \pm .05$ & $\mathbf{. 0 5} \pm .06$ & $.01 \pm .05$ \\
\hline Demings & $39.2 \pm 1.7$ & $\mathbf{4 1 . 7} \pm 2.3$ & $2.5 \pm 2.0$ & Demings & $. \mathbf{0 3} \pm .05$ & $.06 \pm .06$ & $. \mathbf{0 3} \pm .05$ \\
\hline
\end{tabular}

NOTE: Point estimates represent control, treatment, and effect estimates as described under "Model and Estimation". Uncertainty represents $95 \%$ confidence intervals. $N=2,863$ for vote intention and $N=2,829$ for favorability.

The effect of information is statistically significant at a $p<0.05$ level for the four candidates with the lowest levels of name recognition. A global Wald test against the null hypothesis $b_{211}=b_{222}=\ldots=b_{288}=0$ returns $p<0.0001 .^{4}$

Under control, Harris and Warren lead the contenders in terms of favorability by a substantively wide margin. However, after respondents receive information, all candidates (with the exception of the frontrunners)

\footnotetext{
${ }^{4}$ We also investigated spillover effects-i.e., the effect of one candidate's vignette on another candidate's outcome using a global Wald test described in the pre-analysis plan. We failed to find statistically significant spillover effects for either favorability $(p=0.0602)$ or vote choice $(p=0.2394)$. However, the results are suggestive of some caution in extrapolating these results to information-rich environments where, e.g., respondents learn about more than one of the VP candidates in the time period before the general election.
} 
experience a gain in favorability—one that is larger for candidates with lower baseline recognition. This finding suggests that after our simulated campaign messaging, candidate favorability scores converge: candidates with low name recognition—and therefore low baseline favorability—gain, while candidates with high name recognition see negligible effects (Abrams, Harris) or even possibly slightly decline (Warren). As a result, we posit that candidates with low levels of name recognition tend to receive lower ratings in polls than they would actually at the end of a campaign. However, despite significant tightening, there are important differences between the candidates' favorability ratings that persist even after treatment. Duckworth, Bottoms, Baldwin, and Demings all see the largest gains in favorability, yet still remain behind Harris and Warren in our estimates.

\subsection{Vote Intentions}

Our second primary hypothesis was that exposure to our vignettes will move vote intention. In our pre-analysis plan, we noted that we were not expecting large effects here due to the relative difficulty of moving vote intentions. As reported in the right panel of Table 3, we find that the magnitude of effects on vote share are far smaller than their accompanying standard errors and, using a global test, we do not detect statistically significant effects $(p=0.3236)$. However, a failure to reject the null hypothesis does not constitute acceptance of the null hypothesis: in close elections, even a minor advantage in vote share between one candidate and another could be substantively significant. To translate our uncertainty to two-party vote share, our confidence intervals for treatment means would be approximately \pm 4 percentage points. The resulting width ( 8 percentage points) is larger than the two-party margin of victory in all presidential elections since 2000. Thus, we recommend more careful attention to our results on favorability, which serves as a more precise indicator of candidate strength.

\subsection{Subgroup Analyses}

To test the robustness of these findings, we also segment our analyses into politically relevant sub-groups. We consider whether our observed effects hold among the subset of voters who reside in battleground states, are registered to vote, recognize the candidates, and are registered with either the Democratic or Republican Party.

\subsubsection{Battleground States}

As a result of the Electoral College, elections tend to only depend on a few critical battleground states. Compared to a national popular vote, the Electoral College introduces "sizeable" biases (Zingher 2016). Thus, it is important to consider whether our conclusions on a nationally representative sample hold on the arguably more politically salient subset of battleground states. Table 4 reports point estimates and hypothesis tests for $\mathrm{H} 1$ and 
$\mathrm{H} 2$ on the sub-sample of respondents from Wisconsin, Pennsylvania, New Hampshire, Minnesota, Arizona, Florida, Michigan, North Carolina, and Maine. These are the combined "swing states" and "lean Democratic" states in Cook's June 2020 forecast of the 2020 election.

Table 4: Effect of Information on Favorability and Vote Intention (Battleground States)

\begin{tabular}{|c|c|c|c|c|c|c|c|}
\hline \multicolumn{4}{|c|}{ Favorability (0-100) } & \multicolumn{4}{|c|}{ Vote Intention (R: -1, D: 1, NV/DK: 0) } \\
\hline Candidate & Control & Vignette & Effect & Candidate & Control & Vignette & Effect \\
\hline Warren & $\mathbf{4 6 . 8} \pm 4.0$ & $\mathbf{4 3 . 4} \pm 5.1$ & $-\mathbf{3 . 4} \pm 4.5$ & Warren & $.09 \pm .10$ & $.07 \pm .12$ & $-. \mathbf{0 3} \pm .10$ \\
\hline arris & $47.9 \pm 4.2$ & $48.6 \pm 5.3$ & $\mathbf{0 . 7} \pm 4.7$ & Harris & $. \mathbf{0 3} \pm .09$ & $.08 \pm .12$ & $.04 \pm .10$ \\
\hline brams & $.5 \pm 3.8$ & $\mathbf{4 2 . 8} \pm 4.6$ & $-\mathbf{0 . 6} \pm 4.0$ & Abrams & $-.01 \pm .09$ & $.05 \pm .12$ & $.06 \pm .10$ \\
\hline ice & $8 \pm 3.6$ & $\mathbf{4 4 . 1} \pm 4.7$ & $-\mathbf{1 . 7} \pm 4.1$ & Rice & $\mathbf{. 0 3} \pm .08$ & $. \mathbf{0 3} \pm .11$ & $.00 \pm .10$ \\
\hline Duckw & $41.9 \pm 3.7$ & $\mathbf{4 4 . 4} \pm 4.6$ & $\mathbf{2 . 5} \pm 4.1$ & Duckworth & $-.01 \pm .09$ & $.02 \pm .12$ & $.03 \pm .10$ \\
\hline Bottoms & $\mathbf{4 2 . 0} \pm 3.3$ & $\mathbf{4 6 . 1} \pm 4.5$ & $4.2 \pm 4.0$ & Bottoms & $.00 \pm .09$ & $.01 \pm .12$ & $.01 \pm .11$ \\
\hline Baldwin & $\mathbf{4 0 . 0} \pm 3.6$ & $\mathbf{4 0 . 2} \pm 4.4$ & $\mathbf{0 . 2} \pm 3.8$ & Baldwin & $-. \mathbf{0 2} \pm .10$ & $. \mathbf{0 8} \pm .11$ & $.10 \pm .10$ \\
\hline Demings & $\mathbf{4 1 . 2} \pm 3.4$ & $\mathbf{4 2 . 4} \pm 4.4$ & $1.2 \pm 3.8$ & Demings & $-. \mathbf{0 2} \pm .08$ & $-. \mathbf{0 2} \pm .11$ & $.00 \pm .10$ \\
\hline
\end{tabular}

NOTE: Point estimates represent control, treatment, and effect estimates as described under "Model and Estimation" in battleground states. Uncertainty represents $95 \%$ confidence intervals. $N=715$ for vote intention and 707 for favorability.

Within our battleground subset, some trends still hold: Kamala Harris remains the leader in both favorability and vote intention, and we estimate that Elizabeth Warren suffers concerted declines, though sampling variability is large since this analysis discards approximately $3 / 4$ of the sample. A global Wald Test among battleground state respondents returns $p=0.2898$ on favorability. Similarly, echoing our national sample, we do not find significant effects on vote intentions $(p=0.4958)$.

\subsubsection{Registered Voters}

We also consider whether these core results hold among registered voters. While a nationally representative sample is perhaps the best example of the democratic ideal (i.e., it approximates the viewpoints of the governed populace), it may not necessarily mirror the population of eligible voters. Like most early polls, we choose to look at registered voters rather than likely voters to approximate the electorate. 
Table 5: Effect of Information on Favorability and Vote Intention (Registered Voters)

$$
\text { Favorability (0-100) Vote Intention (R: -1, D: 1, NV/DK: 0) }
$$

\begin{tabular}{|c|c|c|c|c|c|c|c|}
\hline Candidate & Control & Vignette & Effect & Candidate & Control & Vignette & Effect \\
\hline Warren & $47.0 \pm 2.2$ & $\mathbf{4 6 . 7} \pm 2.8$ & $-\mathbf{0 . 3} \pm 2.4$ & Warren & $. \mathbf{1 6} \pm .05$ & $. \mathbf{1 6} \pm .06$ & $. \mathbf{0 0} \pm .06$ \\
\hline Harris & $46.9 \pm 2.2$ & $\mathbf{4 7 . 0} \pm 2.8$ & $\mathbf{0 . 1} \pm 2.4$ & & $.14 \pm .05$ & $.16 \pm .07$ & $. \mathbf{0 2} \pm .06$ \\
\hline Abrams & $43.9 \pm 2.0$ & $43.3 \pm 2.6$ & $-\mathbf{0 . 6} \pm 2.3$ & & $. \mathbf{0 8} \pm .05$ & $. \mathbf{0 9} \pm .06$ & $. \mathbf{0 1} \pm .06$ \\
\hline Rice & $\mathbf{4 2 . 9} \pm 2.0$ & $\mathbf{4 5 . 1} \pm 2.6$ & $\mathbf{2 . 2} \pm 2.3$ & Rice & $. \mathbf{0 8} \pm .05$ & $. \mathbf{1 1} \pm .07$ & $. \mathbf{0 3} \pm .06$ \\
\hline Duckworth & $\mathbf{4 1 . 7} \pm 1.9$ & $\mathbf{4 4 . 1} \pm 2.6$ & $\mathbf{2 . 4} \pm 2.3$ & Duckworth & $. \mathbf{0 8} \pm .05$ & $. \mathbf{0 7} \pm .06$ & $-. \mathbf{0 1} \pm .06$ \\
\hline Bottoms & $41.9 \pm 1.9$ & $45.3 \pm 2.5$ & $\mathbf{3 . 4} \pm 2.2$ & Bottoms & $.12 \pm .05$ & $. \mathbf{1 6} \pm .06$ & $.04 \pm .06$ \\
\hline Baldwin & $\mathbf{3 7 . 6} \pm 1.8$ & $\mathbf{4 1 . 1} \pm 2.4$ & $\mathbf{3 . 4} \pm 2.2$ & Baldwin & $.07 \pm .05$ & $.06 \pm .06$ & $. \mathbf{0 0} \pm .06$ \\
\hline Demings & $\mathbf{3 9 . 4} \pm 1.8$ & $\mathbf{4 2 . 5} \pm 2.4$ & $\mathbf{3 . 1} \pm 2.1$ & Demings & $.05 \pm .05$ & $.09 \pm .06$ & $\mathbf{. 0 3} \pm .0$ \\
\hline
\end{tabular}

NOTE: Point estimates represent control, treatment, and effect estimates as described under "Model and Estimation" for the subset of voters who were registered to vote. Uncertainty represents $95 \%$ confidence intervals. $N=2,476$ for registered voters and 2,447 for favorability.

Since over $86 \%$ of the sample reported being a registered voter, these analyses are very similar to our primary results. We observe the same general trend: candidates with low name recognition tend to benefit most from the provision of information. Among registered voters, our global Wald Test on favorability returns $p<0.0001$, and $p=0.7367$ on vote intention.

\subsubsection{Name Recognition}

We also sought to replicate analyses that condition on subjects having name recognition of a candidate. Table 6 reports point estimates and hypothesis tests for our primary hypotheses on the subsample of observations such that $Z_{c i}=1$, where $Z_{c i}$ denotes name recognition from respondent $i$ for candidate $c$ in a regression with an outcome for candidate $c$. 
Table 6: Effect of Information on Favorability and Vote Intention (Name Recognition)

Favorability (0-100)

\begin{tabular}{|c|c|c|c|c|c|c|c|}
\hline ate & & & Effect & & & & \\
\hline Warren & $47.6 \pm 2.2$ & $\mathbf{4 5 . 9} \pm 2.8$ & $-\mathbf{1 . 6} \pm 2.5$ & Warren & $. \mathbf{1 5} \pm .05$ & $. \mathbf{1 2} \pm .06$ & $-. \mathbf{0 3} \pm .06$ \\
\hline Hat & $.0 \pm 2.5$ & $72+2$ & $-\mathbf{1 . 9} \pm 2.8$ & & & $.25 \pm .07$ & $. \mathbf{0 4} \pm .06$ \\
\hline & & $\mathbf{4 7 . 5} \pm 3.3$ & $-.7 \pm 3.0$ & & & & $.01 \pm .07$ \\
\hline Rice & $7.8 \pm 2.7$ & $48.2 \pm 3.5$ & $.4 \pm 3.2$ & Rice & $.12 \pm .07$ & $\mathbf{1 0} \pm .09$ & $-. \mathbf{0 1} \pm .08$ \\
\hline Duckworth & $\mathbf{5 1 . 9} \pm 3.1$ & $\mathbf{5 3 . 2} \pm 3.9$ & $\mathbf{1 . 3} \pm 3.4$ & Duckworth & $.23 \pm .08$ & $.27 \pm .10$ & $.04 \pm .08$ \\
\hline Bottoms & $\mathbf{5 9 . 5} \pm 3.8$ & $\mathbf{5 9 . 2} \pm 4.7$ & $-.3 \pm 4.1$ & Bottoms & $.39 \pm .10$ & $. \mathbf{3 8} \pm .12$ & $-.01 \pm .10$ \\
\hline Baldwin & $\mathbf{5 0 . 5} \pm 3.8$ & $\mathbf{5 1 . 6} \pm 4.7$ & $\mathbf{1 . 2} \pm 4.1$ & Baldwin & $.23 \pm .11$ & $.23 \pm .13$ & $. \mathbf{0 0} \pm .10$ \\
\hline Demings & $\mathbf{5 3 . 8} \pm 4.1$ & $\mathbf{5 5 . 0} \pm 4.9$ & $\mathbf{1 . 1} \pm 4.2$ & Demings & $.30 \pm .10$ & $.26 \pm .13$ & $-.04 \pm .11$ \\
\hline
\end{tabular}

NOTE: Point estimates represent control, treatment, and effect estimates as described under "Model and Estimation" for the subset of voters who identified a particular candidate at the beginning of the survey. Uncertainty represents $95 \%$ confidence intervals. $N=2,450$ for Warren, 2,074 for Harris, 1,592 for Abrams, 1,443 for Rice, 1,076 for Duckworth, 845 for Bottoms, 734 for Baldwin, and 705 for Demings on vote choice. $N=$ 2,410 for Warren, 2,040 for Harris, 1,574 for Abrams, 1,428 for Rice, 1,061 for Duckworth, 839 for Bottoms, 727 for Baldwin, and 695 for Demings on favorability.

A global Wald Test on the name recognition subsample's returns $p=0.7684$ on favorability and $p=0.8383$ on vote intention. In line with our preregistered prediction, our vignettes have smaller effects among those who already knew the candidate, comporting with the logic of our experiment.

Table 6 also highlights that conditioning on name recognition can distort the sample. Respondents who know of, e.g., Demings, represent a non-random subsample of the data. The subjects who do know of Demings might be more predisposed to her due to shared geography, ideology, or because they are aligned on the issues. In fact, we find that conditioning on name recognition greatly inflates favorability, especially for candidates with low name recognition. The conditional-on-name recognition estimate for Demings-the least known candidate-is 13 points larger than the vignette estimate, and over 7 points larger than the conditional-on-name recognition estimate for Warren, Harris and Abrams. Thus, if conditioning on name recognition is designed to approximate general election conditions, it may be severely biased for this goal.

\subsubsection{Party Identification}

Finally, we segment our analysis by political party. Since all of Joe Biden's prospective running mates were Democrats, we are able to compare in-party respondents (Democrats) to out-party ones (Republicans) to un- 
derstand whether partisan affiliations moderate the effects of information on electoral appraisals of candidates.

Table 7: Effect of Information on Favorability and Vote Intention (Democrats)

Favorability (0-100)

\begin{tabular}{|c|c|c|c|c|c|c|c|}
\hline late & Control & & Effect & & & & \\
\hline Warren & $\mathbf{6 4 . 2} \pm 2.9$ & $\mathbf{6 2 . 0} \pm 3.7$ & $-\mathbf{2 . 2} \pm 3.3$ & Warren & $.69 \pm .06$ & $.67 \pm .08$ & $-.02 \pm .07$ \\
\hline & $9 \pm 2.9$ & $0.4 \pm 3.7$ & $-\mathbf{2 . 5} \pm 3.2$ & & & & $-. \mathbf{0 2} \pm .07$ \\
\hline & & & $1.6 \pm 3.0$ & & & & $.01 \pm .07$ \\
\hline Rice & $.3 \pm 2.6$ & $\mathbf{5 8 . 6} \pm 3.4$ & $\mathbf{5 . 3} \pm 3.0$ & KICE & $\mathbf{6 1} \pm .06$ & $.66 \pm .08$ & $.05 \pm .07$ \\
\hline Duckworth & $\mathbf{5 0 . 8} \pm 2.7$ & $\mathbf{5 4 . 3} \pm 3.4$ & $\mathbf{3 . 5} \pm 2.9$ & Duckworth & $. \mathbf{5 9} \pm .06$ & $. \mathbf{5 6} \pm .08$ & $-. \mathbf{0 2} \pm .07$ \\
\hline Botton & $\mathbf{5 1 . 8} \pm 2.5$ & $\mathbf{5 6 . 7} \pm 3.4$ & $4.9 \pm 3.0$ & Bottor & $.60 \pm .06$ & $.66 \pm .08$ & $.06 \pm .07$ \\
\hline Baldwin & $\mathbf{4 5 . 4} \pm 2.5$ & $\mathbf{5 1 . 0} \pm 3.0$ & $\mathbf{5 . 6} \pm 2.7$ & Baldwin & $. \mathbf{5 5} \pm .06$ & $. \mathbf{5 3} \pm .08$ & $-.02 \pm .07$ \\
\hline Demings & $\mathbf{4 7 . 3} \pm 2.6$ & $\mathbf{5 2 . 2} \pm 3.3$ & $4.9 \pm 2.9$ & Demings & $. \mathbf{5 6} \pm .06$ & $.61 \pm .08$ & $. \mathbf{0 5} \pm .07$ \\
\hline
\end{tabular}

NOTE: Point estimates represent control, treatment, and effect estimates as described under "Model and Estimation" for the subset of voters who identified as "Lean Democrat," "Weak Democrat," or "Strong Democrat." Uncertainty represents $95 \%$ confidence intervals. $N=1,317$ for vote intention and 1,305 for favorability. Table 8: Effect of Information on Favorability and Vote Intention (Republicans)

\begin{tabular}{|c|c|c|c|c|c|c|c|}
\hline \multicolumn{4}{|c|}{ Favorability $(0-100)$} & \multicolumn{4}{|c|}{ Vote Intention (R: -1, D: 1, NV/DK: 0) } \\
\hline Candidate & Control & Vignette & Effect & Candidate & Control & Vignette & Effect \\
\hline Warren & $\mathbf{2 9 . 6} \pm 3.1$ & $\mathbf{2 9 . 6} \pm 3.9$ & $.0 \pm 3.4$ & Warren & $-. \mathbf{4 8} \pm .08$ & $-.47 \pm .10$ & $.01 \pm .09$ \\
\hline Harris & $\mathbf{3 1 . 0} \pm 3.0$ & $\mathbf{3 2 . 5} \pm 3.9$ & $\mathbf{1 . 5} \pm 3.5$ & Harris & $-. \mathbf{4 9} \pm .08$ & $-.36 \pm .10$ & $. \mathbf{1 3} \pm .09$ \\
\hline Abrams & $\mathbf{3 1 . 1} \pm 2.9$ & $\mathbf{3 2 . 8} \pm 3.7$ & $1.7 \pm 3.2$ & Abrams & $-.54 \pm .07$ & $-.47 \pm .10$ & $.06 \pm .09$ \\
\hline Rice & $\mathbf{3 2 . 1} \pm 2.9$ & $\mathbf{3 2 . 0} \pm 3.8$ & $-.1 \pm 3.4$ & Rice & $-. \mathbf{5 3} \pm .07$ & $-. \mathbf{4 9} \pm .10$ & $.04 \pm .08$ \\
\hline Duckworth & $31.9 \pm 2.7$ & $\mathbf{3 5 . 1} \pm 3.8$ & $3.2 \pm 3.4$ & Duckworth & $-.52 \pm .07$ & $-.49 \pm .10$ & $.04 \pm .09$ \\
\hline Bottoms & $\mathbf{3 2 . 2} \pm 2.8$ & $32.2 \pm 3.7$ & $. \mathbf{1} \pm 3.3$ & Bottoms & $-. \mathbf{4 6} \pm .08$ & $-.48 \pm .10$ & $-.02 \pm .09$ \\
\hline Baldwin & $\mathbf{2 9 . 4} \pm 2.7$ & $\mathbf{3 1 . 4} \pm 3.7$ & $\mathbf{2 . 0} \pm 3.3$ & Baldwin & $-. \mathbf{5 1} \pm .07$ & $-. \mathbf{5 1} \pm .10$ & $.00 \pm .09$ \\
\hline Demings & $\mathbf{3 1 . 1} \pm 2.7$ & $\mathbf{3 0 . 4} \pm 3.5$ & $-.8 \pm 3.1$ & Demings & $-. \mathbf{5 4} \pm .07$ & $-.56 \pm .10$ & $-. \mathbf{0 2} \pm .08$ \\
\hline
\end{tabular}

NOTE: Point estimates represent control, treatment, and effect estimates as described under "Model and Estimation" for the subset of voters who identified as "Lean Republican," "Weak Republican," or "Strong Republican." Uncertainty represents $95 \%$ confidence intervals. $N=1,130$ for vote intention and 1,116 for favorability.

Our results show that the effects of our vignette are primarily localized to Democratic respondents. We reject the global null of no effect on favorability among Democratic respondents $(p<0.0001)$, but fail to reject for Republican respondents ( $p=0.5638)$. As in the national sample, across both parties, we fail to reject the 
null hypothesis on vote intentions ( $p=0.4403$ for Democrats and $p=0.1569$ for Republicans).

\section{Conclusion}

The academic literature widely holds that early polling lacks predictive power toward the eventual election outcome because it fails to replicate the information environment that voters will face. Using narratives and attacks from the past, we develop a method to equip voters with the information they are likely to have by the election. Testing our procedure on the 2020 Democratic vice presidential process, we find that as expected, information does substantially alter favorability. Before voters receive information, the leaders in name recognition, Elizabeth Warren and Kamala Harris, are also evaluated most favorably by respondents. But when respondents receive information, Warren and Harris largely maintain their positions, while Bottoms, Rice, and Duckworth - all of whom have low name recognition - see gains. This finding suggests that candidate evaluations tend to equalize after hearing competing narratives. Taken together, our results demonstrate inadequacies in conventional polling that lead researchers to understate support for lesser-known candidates. We believe future polling, especially when considering candidates with low name recognition, should incorporate some form of informational vignettes to mitigate some of the bias arising from name recognition.

\section{References}

Arnesen, Sveinung, Dominik Duell, and Mikael Poul Johannesson (Feb. 2019). "Do citizens make inferences from political candidate characteristics when aiming for substantive representation?" In: Electoral Studies 57, pp. 46-60. ISSN: 0261-3794. URL: http://www . sciencedirect.com/science/article/pii/ S0261379418302257.

Barnes, Tiffany D., Emily Beaulieu, and Gregory W. Saxton (Jan. 2020). "Sex and corruption: how sexism shapes voters' responses to scandal”. In: Politics, Groups, and Identities 8.1. Publisher: Routledge _eprint: https://doi.org/10.1080/21565503.2018.1441725, pp. 103-121. ISSN: 2156-5503. URL: https : // doi . org/10.1080/21565503.2018.1441725.

Broockman, David and Joshua Kalla (Feb. 2020). "Candidate Ideology and Vote Choice in the 2020 US Presidential Election”. In: Publisher: OSF Preprints. URL: https://osf .io/25wm9/.

Coppock, Alexander and Oliver A. McClellan (Jan. 2019). "Validating the demographic, political, psychological, and experimental results obtained from a new source of online survey respondents". In: Research \& 
Politics 6.1, p. 205316801882217. ISSN: 2053-1680, 2053-1680. URL: http : / journals . sagepub . com/doi/10.1177/2053168018822174.

Doherty, David, Conor M. Dowling, and Michael G. Miller (Oct. 2011). "Are Financial or Moral Scandals Worse? It Depends.” In: PS: Political Science \& Politics 44.04, pp. 749-757. ISSN: 1049-0965, 1537-5935. URL: http://www. journals. cambridge.org/abstract_S1049096511001247.

- (Apr. 2014). "Does Time Heal All Wounds? Sex Scandals, Tax Evasion, and the Passage of Time". In: PS: Political Science \& Politics 47.02, pp. 357-366. ISSN: 1049-0965, 1537-5935. URL: http: //www . journals. cambridge.org/abstract_S1049096514000213.

Eggers, Andrew C., Nick Vivyan, and Markus Wagner (Jan. 2018). "Corruption, Accountability, and Gender: Do Female Politicians Face Higher Standards in Public Life?” In: The Journal of Politics 80.1. Publisher: The University of Chicago Press, pp. 321-326. ISSN: 0022-3816. URL: https : //www . journals . uchicago.edu/doi/abs/10.1086/694649.

Funk, Carolyn L. (Mar. 1996). "The impact of scandal on candidate evaluations: An experimental test of the role of candidate traits". In: Political Behavior 18.1, pp. 1-24. ISSN: 1573-6687. URL: https : / doi . org/10.1007/BF01498658.

Gaskins, Ben et al. (Mar. 2018). "From the FEC to the Ballot Box: Voter Accountability for Campaign Finance Law Violations:" in: American Politics Research. Publisher: SAGE PublicationsSage CA: Los Angeles, CA. URL: https://journals . sagepub.com/doi/10.1177/1532673X18759641.

Gelman, Andrew and Gary King (1993). "Why Are American Presidential Election Campaign Polls so Variable When Votes Are so Predictable?” In: British Journal of Political Science 23.4. Publisher: Cambridge University Press, pp. 409-451. ISSN: 0007-1234. URL: https://www . jstor.org/stable/194212.

Hainmueller, Jens, Dominik Hangartner, and Teppei Yamamoto (Feb. 2015). "Validating vignette and conjoint survey experiments against real-world behavior". In: Proceedings of the National Academy of Sciences 112.8. Publisher: National Academy of Sciences Section: Social Sciences, pp. 2395-2400. ISSN: 00278424, 1091-6490. URL: https://www. pnas .org/content/112/8/2395.

Incerti, Trevor (2020). "Corruption Information and Vote Share: A Meta-Analysis and Lessons for Experimental Design”. In: American Political Science Review (). Publisher: Cambridge University Press, pp. 1-14. ISSN: 0003-0554, 1537-5943. URL: https : / / www . cambridge . org/ core / journals / americanpolitical - science - review / article / corruption - information - and - vote - share - a metaanalysis-and-lessons-for-experimental-design/AB2ACE468B04EAB85CAF7379F9DF4817. 
Kam, Cindy D. and Elizabeth J. Zechmeister (2013). "Name Recognition and Candidate Support”. In: American Journal of Political Science 57.4. _eprint: https://onlinelibrary.wiley.com/doi/pdf/10.1111/ajps.12034, pp. 971-986. ISSN: 1540-5907. URL: https : / / onlinelibrary . wiley . com/doi / abs / 10 . 1111 / ajps.12034.

Panagopoulos, Costas and Donald P. Green (2008). "Field Experiments Testing the Impact of Radio Advertisements on Electoral Competition”. In: American Journal of Political Science 52.1. Publisher: [Midwest Political Science Association, Wiley], pp. 156-168. ISSN: 0092-5853. URL: https : //www . jstor . org/ stable/25193803.

Zingher, Joshua (Apr. 2016). "The relationship between bias and swing ratio in the Electoral College and the outcome of presidential elections". In: Journal of Elections, Public Opinion and Parties 26.2, pp. $232-252$. ISSN: 1745-7289, 1745-7297. URL: http://www.tandfonline.com/doi/full/10.1080/17457289. 2016.1145686.

\section{Appendix}

\section{A Summary Statistics}

Table 9: Demographics of the Sample

\begin{tabular}{lrr}
\multicolumn{4}{c}{ Summary Statistics } \\
Variable & Mean & SD \\
Female & $\mathbf{. 5 2}$ & $\mathbf{. 5 0}$ \\
Age & $\mathbf{4 6}$ & $\mathbf{1 7}$ \\
High School Degree & $\mathbf{. 9 7}$ & $\mathbf{. 1 7}$ \\
Bachelor's Degree & $\mathbf{. 4 3}$ & $\mathbf{. 4 9}$ \\
Household Income & $\mathbf{6 6 , 0 9 1 . 5 4}$ & $\mathbf{6 5 , 3 5 6 . 5 8}$ \\
Democrat & $\mathbf{. 4 6}$ & $\mathbf{. 5 0}$ \\
Republican & $\mathbf{. 3 9}$ & $\mathbf{. 4 9}$ \\
Northeast & $\mathbf{. 2 1}$ & $\mathbf{. 4 1}$ \\
Midwest & $\mathbf{. 1 9}$ & $\mathbf{. 4 0}$ \\
South & $\mathbf{. 3 9}$ & $\mathbf{. 4 9}$ \\
West & $\mathbf{. 2 0}$ & $\mathbf{. 4 0}$ \\
Battleground State & $\mathbf{. 2 5}$ & $\mathbf{. 4 3}$ \\
Registered Voters & $\mathbf{. 6 6}$ & $\mathbf{. 3 4}$
\end{tabular}


NOTE: Point estimates represent control, treatment, and effect estimates as described above. Uncertainty represents $95 \%$ confidence intervals. $N=2,866$ 


\section{B Vignettes}

The following are the vignettes that were displayed to the treatment group. Each treated respondent saw three randomly selected vignettes.

ELIZABETH WARREN: Elizabeth Warren is a United States Senator from Massachusetts. Warren grew up in Oklahoma on the ragged edge of the middle class. After dropping out of college at age 19, Warren was able to return to school at a public college and fulfill her lifelong dream of becoming a teacher. Eventually, she enrolled in law school, and became a professor of bankruptcy law at Harvard, where she dedicated her career to studying why families go broke. After the 2008 financial crisis, Warren fought to create the Consumer Financial Protection Bureau, which has already saved consumers $\$ 12$ billion. Her time in the Senate, and her 2020 primary campaign for the Democratic nomination for president centered on a fight against the big money and special interests that she saw as corrupting politics. Following her unsuccessful 2020 bid, Warren has pushed for oversight of the Trump Administration's coronavirus efforts.

Critics say that Warren is too far to the left to be the Democratic Vice Presidential nominee: she has signed onto plans like Medicare for All and the Green New Deal that could balloon the deficit and raise taxes. During her presidential campaign, Warren proposed taxes that some critics say would raise the income tax rate above $100 \%$ for some individuals. In addition, they say that she does not sufficiently respect the struggles faced by communities of color: critics note that while serving as a law school professor, Warren falsely claimed to be Native American, and was listed as a minority faculty member.

KAMALA HARRIS: Kamala Harris is a United States Senator from California. The daughter of immigrants from India and Jamaica, she was raised by a single mother, before attending Howard University, and UC Hastings Law School. A life-long public servant, Harris served as Attorney General of California, where she prosecuted transnational gangs that exploited women and children, won billions for homeowners against the big banks, and fought for marriage equality nationwide. During her four years in the United States Senate, she has introduced or co-sponsored legislation to provide sweeping tax cuts for the middle class, address the high cost of rent, raise the minimum wage to $\$ 15$ an hour, and expand access to affordable, quality health care. Following her unsuccessful 2020 presidential primary campaign, Harris has been at the forefront of legislation to address racism and reform the criminal justice system.

Critics argue that Harris has been too inconsistent to be Vice President: while she co-sponsored Senator Bernie Sanders's Medicare for All bill in the Senate, she embraced a more moderate approach just two years later during the presidential campaign. Critics also contend that Harris's behavior while Attorney General was needlessly harsh, and that she embraced unjust practices leading to mass incarceration. Harris's office 
fought to uphold wrongful convictions, prosecuted thousands of marijuana cases, and refused to mandate investigations of all officer-involved lethal shootings. Harris has also been criticized for her anti-truancy program that threatened to prosecute parents whose children skipped school.

STACEY ABRAMS: Stacey Abrams is the former Minority Leader of the Georgia House of Representatives. The daughter of two reverends, she grew up as one of six children in a family that struggled to make ends meet, before attending Spelman College, the University of Texas, and Yale Law School. After graduating from law school, she started a small business, wrote a series of romance novels, and founded a non-profit that registers minority voters. During her ten years in Georgia's House of Representatives, she stopped a bill to raise taxes on working people, negotiated compromises with Republicans on infrastructure, transportation, and education, and fought attempts to roll back reproductive rights. Following her unsuccessful 2018 bid to become the first Black woman governor of Georgia, Abrams has been an advocate for voting rights.

Critics say that Abrams leans too far to the left to be Vice President: they allege that she has supported higher taxes and advocated a government takeover of health care, though supporters say these are misrepresentations. Critics also point to the fact that she owed more than $\$ 50,000$ in back taxes and her failure to concede the 2018 Georgia gubernatorial election as evidence that she does not think the rules apply to her. They also question her inexperience, noting that she has never held federal or statewide office, and has little experience in foreign policy and national security.

SUSAN RICE: Susan Rice is the former United States National Security Advisor and Ambassador to the United Nations. Born to a family of policymakers, Rice attended Stanford University, before receiving a Rhodes Scholarship to pursue a doctorate in International Relations at Oxford. After graduation, Rice served in a variety of foreign policy roles in the Clinton Administration. After working in the private sector and think tanks for a decade, Rice returned to the Obama Administration as the first Black Ambassador to the United Nations in United States history. At the United Nations, Rice worked to promote human rights and American interests. In 2013, she was appointed United States National Security Advisor, where she was responsible for conducting daily briefings for the President and responsible for coordinating response to all threats to national security. Her tenure included the response to the Ebola Crisis and the development of the Iran Nuclear Deal. Since leaving the Obama Administration, Rice has been a Distinguished Research Fellow at American University.

Critics say that Rice is not trustworthy enough to be the Democratic Vice Presidential nominee. In 2012, she was accused of downplaying the severity of the Benghazi attacks, and stating misinformation during Sunday morning shows, though some major news outlets have debunked these claims. In addition, critics claim that Rice acted improperly by requesting and obtaining the names of Trump Campaign officials on intercepted 
foreign communications, though analysis by major news outlets concluded that she followed ordinary protocols. Critics also suggest that she lacks the experience to be Vice President, as she has never held elected office before and does not have experience in the legislative process.

TAMMY DUCKWORTH: Tammy Duckworth is a United States Senator from Illinois. Born to a ThaiAmerican military family, Duckworth attended college at the University of Hawaii, before receiving an MA in International Relations from George Washington University and a doctorate in Human Services from Capella University. In 2013, Duckworth's National Guard unit was mobilized and she became a combat helicopter pilot during the Iraq War. In 2004, Duckworth's helicopter was hit by a rocket propelled grenade. She lost both legs and partial use of her right arm in the explosion, but declined retirement to continue as a Lieutenant Colonel in the Illinois Army National Guard. As a result of her injuries, Duckworth earned a Purple Heart. Since then, Duckworth has been an advocate for veterans, serving as Director of the Illinois Department of Veterans Affairs, and U.S. Assistant Secretary of Veterans Affairs. After serving four years in the House of Representatives, Duckworth was elected to the US Senate in 2012, where she has fought for equal rights, veterans, and to protect Medicare and Social Security.

Critics note that during her tenure at the Illinois VA, whistleblowers accused her of ignoring claims of corruption and abuse, though the lawsuit was settled with no admission of wrongdoing. In addition, critics cite a 2016 investigation by the Chicago Tribune that found little evidence that her signature programs at the VA had produced substantial effects, and that Duckworth failed to be the main sponsor on a single bill that became law while in the House of Representatives as evidence of ineffectiveness. Critics also questioned Duckworth's patriotism after she called for a dialogue about taking down statues of George Washington.

KEISHA LANCE BOTTOMS: Keisha Lance Bottoms is the Mayor of Atlanta. The daughter of R\&B icon Major Lance, Bottoms graduated from Florida A\&M University before receiving her law degree at Georgia State University. She lives in Atlanta with her husband and four adopted children. Before serving as Mayor, Bottoms was a Judge and member of the City Council. As Mayor, Bottoms has promoted equal rights, criminal justice reform, and a far-reaching plan to increase the financial transparency of the city government. Bottoms's tenure has also been marked by clashes with the Trump Administration: she signed an Executive Order banning ICE from holding detainees in Atlanta prisons. Following the murder of George Floyd, Bottoms received widespread national attention for both her efforts to promote racial justice, and her pleas for non-violence among protestors.

Critics say Bottoms lacks the experience to be Vice President: Bottoms has never held federal office before, and has no track record in either foreign policy or national security. Additionally, following reports of major 
walkouts at the Atlanta Police Department and unrest across the city this year, critics have alleged that she is unable to keep her city under control. She has also faced criticism for attempts to quash an ethics investigation into whether city funds were improperly used to pay campaign staffers, and received a subpoena from the State Ethics Commission over allegations of campaign finance violations.

TAMMY BALDWIN: Tammy Baldwin is a United States Senator from Wisconsin. Born to a mother who struggled with mental illness, chronic pain, and drug abuse, Baldwin was raised by her grandparents in Madison. After attending college at Smith College and law school at the University of Wisconsin Law School, Baldwin served in the Wisconsin State Assembly before winning a seat in Congress. In 1998, Baldwin became the first openly gay non-incumbent to be elected to the United States House of Representatives. In Congress, Baldwin was a fierce defender of working families, and fought to expand health care access. She was one of only a handful of votes against repealing the Glass-Steagall Act, which separated risky investment banking from traditional banking. In 2012, Baldwin was elected to the United States Senate. As Senator, she has championed Buy American rules, confronted unfair trade deals, and worked across party lines to ensure that veterans are supported with quality health care, jobs, and community support.

Critics say that Baldwin is too far to the left to be the Democratic Vice Presidential nominee: she has signed onto plans like Medicare for All that could balloon the deficit and raise taxes. In addition, they cite Baldwin's handling of a scandal at the VA in Tomah, WI as evidence that she lacks proper judgment. Critics note that Baldwin's office received a report outlining overprescription of opioids in 2014. Baldwin did not go public with the report until the scandal made headline news. Moreover, critics say that she fired a top aide to cover up the scandal, though a Senate ethics panel found that this charge "lacked merit".

VAL DEMINGS: Val Demings is a member of the United States House of Representatives from Florida. The youngest of seven children and the first in her family to graduate college, Demings worked as a social worker after graduating from Florida State University, before joining the Orlando Police Department and later earning a Masters degree at Webster University. In 2007, Demings became Chief for the Orlando Police Department-the first woman and first Black woman to hold the position. Over her tenure, violent crime fell by 40\%. During her four years in Congress, Demings has served on the Committee on Homeland Security, the Select Committee on Intelligence, and the House Judiciary Committee. She is also the Vice-Chair of the Gun Violence Prevention Task Force and was appointed an Impeachment Manager by Speaker of the House Nancy Pelosi, where she spearheaded the impeachment investigation into President Trump.

Critics say that Demings' poor record on police brutality disqualifies her from the Vice Presidency: under her watch, the Orlando Police Department used force 574 times, $20 \%$ more than in comparable cities. In ad- 
dition, during her tenure as Chief, the Orlando Police Department was forced to pay millions in settlements in nearly fifty lawsuits alleging misconduct. They also point to her personal record as an officer as evidence of a lack of sound judgement: in 2009, Demings was censured after her gun was stolen from her unlocked truck.

The following are the placebo vignettes received by the control group. Each respondent saw all three vignettes in randomized order.

INCEPTION: Inception is a 2010 science fiction action film written and directed by Christopher Nolan, who also produced the film with his wife, Emma Thomas. The film stars Leonardo DiCaprio as a professional thief who steals information by infiltrating the subconscious of his targets. He is offered a chance to have his criminal history erased as payment for the implantation of another person's idea into a target's subconscious.

After the 2002 completion of Insomnia, Nolan presented to Warner Bros. a written 80-page treatment for a horror film envisioning "dream stealers," based on lucid dreaming. Deciding he needed more experience before tackling a production of this magnitude and complexity, Nolan shelved the project and instead worked on 2005's Batman Begins, 2006's The Prestige, and The Dark Knight in 2008. The treatment was revised over 6 months and was purchased by Warner in February 2009. Inception was filmed in six countries, beginning in Tokyo on June 19 and ending in Canada on November 22. Its official budget was US\$160 million, split between Warner Bros and Legendary. Nolan's reputation and success with The Dark Knight helped secure the film's US\$100 million in advertising expenditure.

Inception's premiere was held in London on July 8, 2010; it was released in both conventional and IMAX theaters beginning on July 16, 2010. Inception grossed over US\$829 million worldwide, becoming the fourth highest-grossing film of 2010. Considered one of the best films of the 2010s, Inception received critical praise for its screenplay, direction, themes, visual effects, musical score, and ensemble cast.

ALICE IN WONDERLAND: Alice in Wonderland is a 2010 American dark fantasy adventure film directed by Tim Burton from a screenplay written by Linda Woolverton. Loosely inspired by Lewis Carroll's fantasy novels, Alice's Adventures in Wonderland and Through the Looking-Glass, and Walt Disney's 1951 animated film of the same name, the film tells the story of a nineteen-year-old Alice Kingsleigh, who is told that she can restore the White Queen to her throne, with the help of the Mad Hatter. She is the only one who can slay the Jabberwocky, a dragon-like creature that is controlled by the Red Queen and terrorizes Underland's inhabitants. In this situation, Alice fights against the Red Queen to protect the world.

Alice in Wonderland was produced by Walt Disney Pictures and shot in the United Kingdom and the United States. The film premiered in London at the Odeon Leicester Square on February 25, 2010, and was released 
in the United Kingdom and the United States through the Disney Digital 3D, RealD 3D, and IMAX 3D formats as well as in conventional theaters on March 5, 2010. It is also the second-highest-grossing film of 2010.

Alice in Wonderland received mixed reviews upon release; although praised for its visual style and special effects, the film was criticized for its lack of narrative coherence. It received three nominations at the 68th Golden Globe Awards, including Best Motion Picture - Musical or Comedy. At the 83rd Academy Awards, Alice in Wonderland won Best Art Direction and Best Costume Design, and was also nominated for Best Visual Effects. The film generated over $\$ 1.025$ billion in ticket sales and became the fifth highest-grossing film of all time during its theatrical run.

TOY STORY 3: Toy Story 3 is a 2010 American computer-animated comedy film produced by Pixar Animation Studios for Walt Disney Pictures. It is the third installment in Pixar's Toy Story series, and the sequel to 1999's Toy Story 2. It was directed by Lee Unkrich, the editor of the first two films and the co-director of Toy Story 2, written by Michael Arndt, while Unkrich wrote the story along with John Lasseter and Andrew Stanton, respectively, director and co-writer of the first two films.

The plot focuses on Woody, Buzz Lightyear, and Andy's other remaining toys accidentally being donated to a day care center, while Andy, now 17 years old, is preparing to leave for college, and their ensuing race to get home before Andy leaves.

The film was released in theaters June 18,2010, and played worldwide from June through October in the Disney Digital 3-D, RealD, and IMAX 3D formats. Toy Story 3 was the first film to be released theatrically with Dolby Surround 7.1 sound. Like its predecessors, Toy Story 3 received critical acclaim upon release, with critics praising the vocal performances, screenplay, emotional depth, animation, and Randy Newman's musical score. 


\section{Missing Favorability Data, Midpoint Imputation Results}

Table 10: Effect of Information on Favorability (Midpoint Imputed)

Favorability (0-100)

$\begin{array}{lrrr}\text { Candidate } & \text { Control } & \text { Vignette } & \text { Effect } \\ \text { Warren } & \mathbf{4 6 . 3} \pm 2.0 & \mathbf{4 5 . 1} \pm 2.6 & -\mathbf{1 . 2} \pm 2.3 \\ \text { Harris } & \mathbf{4 6 . 4} \pm 2.0 & \mathbf{4 6 . 3} \pm 2.5 & \mathbf{0 . 0} \pm 2.3 \\ \text { Abrams } & \mathbf{4 3 . 3} \pm 1.8 & \mathbf{4 3 . 5} \pm 2.4 & \mathbf{0 . 2} \pm 2.1 \\ \text { Rice } & \mathbf{4 2 . 3} \pm 1.8 & \mathbf{4 4 . 5} \pm 2.4 & \mathbf{2 . 2} \pm 2.1 \\ \text { Duckworth } & \mathbf{4 1 . 3} \pm 1.8 & \mathbf{4 4 . 6} \pm 2.4 & \mathbf{3 . 4} \pm 2.1 \\ \text { Bottoms } & \mathbf{4 1 . 8} \pm 1.7 & \mathbf{4 4 . 7} \pm 2.3 & \mathbf{2 . 9} \pm 2.1 \\ \text { Baldwin } & \mathbf{3 7 . 8} \pm 1.7 & \mathbf{4 1 . 2} \pm 2.2 & \mathbf{3 . 5} \pm 2.0 \\ \text { Demings } & \mathbf{3 9 . 4} \pm 1.7 & \mathbf{4 1 . 9} \pm 2.2 & \mathbf{2 . 5} \pm 2.0\end{array}$

These results treat any non-answers on the favorability outcome as 50/100. 